\title{
Left Hepatectomy Through Double Approach and Total Vascular Exclusion for Giant Left Lobe Hepatocarcinoma
}

\author{
NICOLAE BACALBASA ${ }^{1,2}$, IRINA BALESCU ${ }^{3}$, SIMONA DIMA $^{2}$, LUCIAN ALECU ${ }^{4}$ and IRINEL POPESCU 5,6 \\ ${ }^{1}$ Department of Obstetrics and Gynecology, "Carol Davila" University of Medicine and Pharmacy, Bucharest, Romania; \\ ${ }^{2}$ Department of Visceral Surgery, Center of Excellence in Translational Medicine, \\ "Fundeni" Clinical Institute, Bucharest, Romania; \\ ${ }^{3}$ Department of Visceral Surgery, "Ponderas Academic Hospital”, Bucharest, Romania; \\ ${ }^{4}$ The General Surgery Clinic, the Emergency Clinical Hospital "Prof. Dr. Agrippa Ionescu", Bucharest, Romania; \\ ${ }^{5}$ Department of Visceral Surgery, "Fundeni" Clinical Institute, Bucharest, Romania; \\ 6"Titu Maiorescu" University of Medicine and Pharmacy, Bucharest, Romania
}

\begin{abstract}
Background/Aim: Hepatocellular carcinoma represents the most frequently encountered liver malignancy worldwide; however the dimensions of these lesions rarely surpass $20 \mathrm{~cm}$. In such cases surgical treatment might encounter significant technical difficulties. Case Report: We present the case of a 49-year-old patient diagnosed with a 22/25/21 cm left lobe hepatocellular carcinoma. Results: In order to achieve a safe and effective resection total vascular exclusion was needed. Moreover, due to the anatomical relationship between the tumor and the cava vein, an intrathoracic approach of the inferior cava vein was the option of choice. The time of total vascular exclusion was of 26 minutes while the length of surgery was of 210 minutes; meanwhile the estimated blood loss was of $650 \mathrm{ml}$, while the postoperative outcome was uncomplicated. Conclusion: Total vascular exclusion by double approach might be a safe alternative in order to minimize the risks of severe intraoperative and postoperative complications.
\end{abstract}

Hepatocellular carcinoma represents the most common malignant tumor affecting the liver, being more frequently encountered in men then in women; therefore, it represents the fifth most common neoplastic disease in male patients and the seventh most commonly encountered neoplasia in female patients $(1,2)$. Whenever hepatocellular carcinoma is

This article is freely accessible online.

Correspondence to: Irina Balescu, "Ponderas" Academic Hospital, Nicolae Caramfil 85a Street, Bucharest, Romania. Tel: +40 724077709, e-mail: irina.balescu@ ponderas-ah.ro

Key Words: Hepatocellular carcinoma, resection, vascular exclusion, liver tumor. suspected, the first intention treatment which should be taken in consideration is the surgical one; however, the decision of submitting to surgery such patients is taken after meticulous analysis of each case. Not only the dimension of the tumor, but also the liver function and association of other comorbidities represent significant criteria that should be carefully analysed $(3,4)$.

\section{Case Report}

After obtaining the approval of the Ethical Committee no $312 / 2020$, data of the patient were reviewed and presented in the current paper. The 49 year old patient with good general condition self-presented for diffuse abdominal pain, nausea and weight loss. The anamnesis revealed no significant medical antecedents; the patient had been submitted to appendectomy at the age of 15 and presented no history of hepatitis or other chronic viral infection, no previous exposure to toxic agents and denied chronic alcohol consumption. Meanwhile no significant family history of malignant diseases was revealed.

\section{Results}

The 49-year-old patient with no significant medical antecedents was initially investigated for diffuse abdominal pain, nausea and weight loss of $15 \mathrm{~kg}$ in the last 6 months. The patient was submitted to an abdominal ultrasound which revealed the presence of a large hepatic mass located at the level of the left hepatic lobe measuring 22/25/21 cm while the remnant parenchyma presented normal aspect.

The patient was further submitted to a computed tomography which confirmed the presence of this large hepatic tumor entirely deforming the left lobe, with no other suspect nodules at the level of the remnant parenchyma. 
Meanwhile, no other pathological aspects were observed; however, the patient was further submitted to upper and lower digestive endoscopy in order to exclude the metastatic origin of the lesion but no lesion was found. The serological tests for hepatitis demonstrated the absence of viral infections while the serum levels of tumoral markers demonstrated the presence of a high level of alpha fetoprotein (AFP) as well as an increased level of serum carcinoembrionic antigen (CEA); therefore the serum levels of AFP were $734 \mathrm{ng} / \mathrm{ml}$ while the serum levels of CEA were $598 \mathrm{ng} / \mathrm{ml}$. Due to the fact that the imaging studies demonstrated the presence of a very well developed vascularization of the tumor preoperative biopsy was not performed, the patient being submitted to surgery. Intraoperatively, due to the local anatomical conditions giant tumor, very well developed vascular network - total vascular exclusion was needed; therefore the abdominal incision was prolonged at the level of the thorax and the diaphragm was sectioned in order to achieve an adequate approach of the suprahepatic cava vein. In these conditions total vascular exclusion by clamping the portal pedicle, the suprahepatic veins and the intrathoracic cava vein were performed. Once this manoeuvre was completed, the left lobe was completely mobilized and atypical left hepatectomy was performed with no intraoperative incidents (Figures 1, 2, 3, 4 and 5). The total time of complete vascular exclusion was 26 minutes while the length of surgery was 210 minutes; meanwhile the estimated blood loss was of $650 \mathrm{ml}$, the patient being transfused with one unit of erithrocitic mass. The histopathological studies demonstrated the presence of a 24/22/21 cm well differentiated hepatocarcinoma.

\section{Discussion}

According to their dimensions, liver tumors are classified as small $(<5 \mathrm{~cm})$, big $(5-10 \mathrm{~cm})$ and giant $(>10 \mathrm{~cm})$; meanwhile, tumors larger than $20 \mathrm{~cm}$ are extremely rare (5, $6)$. In such conditions the treatment of choice remains surgery, especially in otherwise healthy patients presenting no other significant comorbidities (7); however, the surgical technique should be adapted in each case due the anatomical particularities of each case and due to the high risks of developing intra- and postoperative life threatening complications such as fulminant, uncontrollable intraoperative haemorrhage or postoperative acute liver dysfunction due to the low remnant volume of functional parenchyma (9-13). Therefore, in order to prevent the development of an intractable intraoperative bleeding, in the case we presented a total vascular exclusion was the option of choice; moreover, an intrathoracic control of the inferior cava vein was preferred due to the extent of the lesion. As for the risk of postoperative acute liver failure, this complication was prevented in our case due to the presence

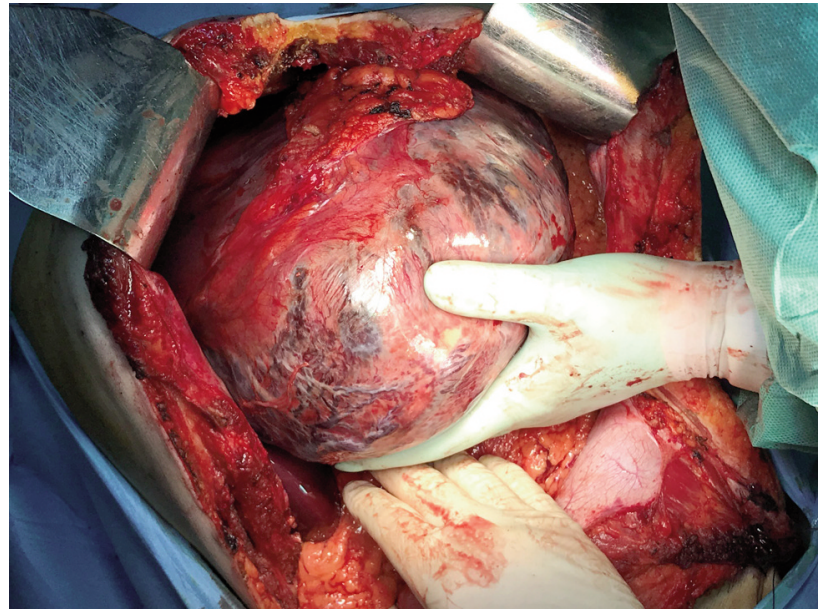

Figure 1. Initial intraoperative aspect-large tumor located at the level of the left hemiliver; in order to have a better access on the inferior cava vein the abdominal incision was prolonged at the level of the thorax.



Figure 2. The aspect after complete vascular exclusion and mobilization of the tumor. Preparing the transection of the liver parenchyma.

of a perfectly normal function of the right lobe, fact which was also demonstrated by the presence of preoperative normal serum levels of liver enzymes $(6,8)$.

In order to minimize the risks of perioperative complications in patients submitted to surgery for such a complex pathology, different study groups such as Barcelona Clinic Liver Cancer (BCLC), American/European Association for the Study of Liver Diseases created different staging and stratification systems aiming to identify cases which could benefit most after surgery $(3,4)$. Therefore, the most important factors that should be taken in consideration 


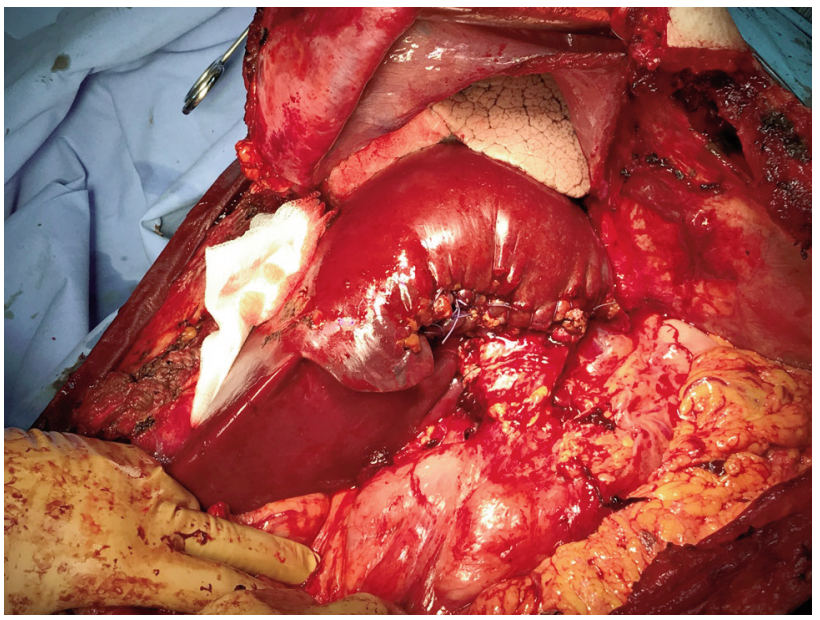

Figure 3. The final aspect after typical left hepatectomy, before suturing the diaphragm.

before deciding to perform an extended liver resection for large hepatocellular carcinomas are represented by the performance status, the functionality of the remnant liver, the presence of underlying liver disease (characterised by the presence and degree of portal hypertension), stage of disease and feasibility of complete and safe resection (14).

When it comes to the most severe complications which might develop intraoperatively, particular attention should be paid to the risk of perioperative bleeding. Therefore, it is widely known the fact that intraoperative bleeding and blood transfusions seem to negatively impact on the long-term outcomes, being related with a higher rate of local recurrences and lower rates of disease-free survival (15-17). In this respect, in order to minimize the intraoperative bleeding rate and the necessity of blood transfusion various technical approaches have been proposed, Pringle maneuver, selective, hemiselective or total vascular exclusion being the most commonly investigated surgical techniques (18). Initially imagined by J. H. Pringle in 1908, the maneuver with the same name has been widely used initially in order to reduce the intraoperative blood loss and to diminish the necessity of intraoperative transfusions $(19,20)$. However, the method seems to have certain disadvantages such as the one of inducing warm ischemia and ischemia reperfusion lesions (21). This fact seems to be correlated with the development of transient increase of the transaminases during the early postoperative period but also with a higher risk of developing liver recurrences. Therefore, it seems that prolongation of the time of warm ischemia might induce local hypoxia and increased cytokine activity increasing in this way the rate of proliferation of hepatic cells and the risk of postoperative recurrence; in this respect decreased

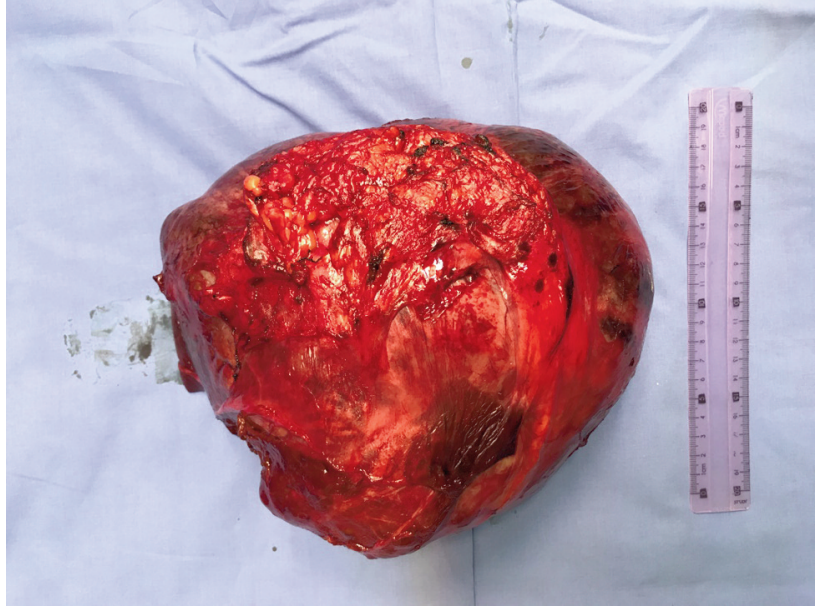

Figure 4. The specimen - the left lobe is entirely transformed and included in the tumorl mass.

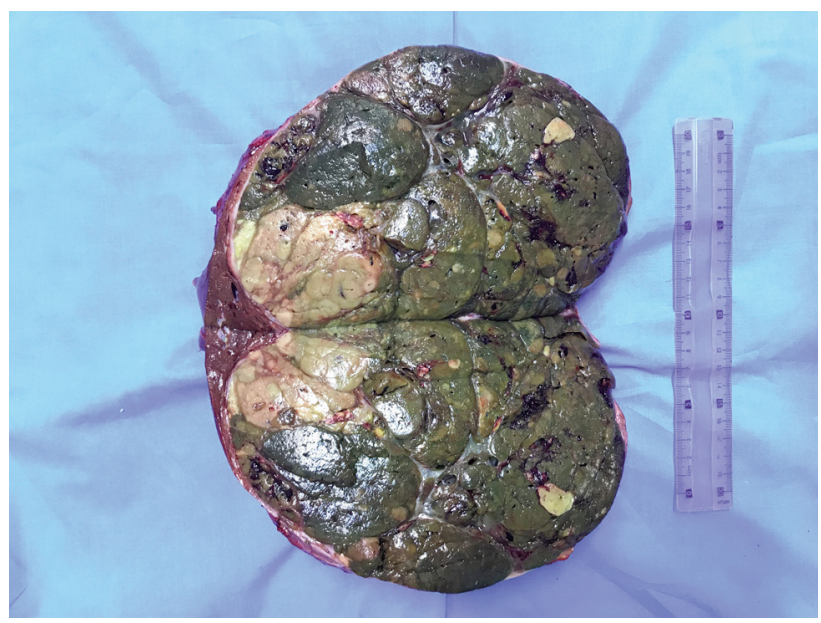

Figure 5. Transected specimen measuring 24/22/21 cm. The histopathological studies demonstrated the presence of a well differentiated hepatocarcinoma.

recurrence-free survival intervals have been reported in cases submitted to longer times of liver induced ischemia (22-24). One of the most suggestive studies which stated this aspect was conducted by Liu et al. and demonstrated that application of Pringle manoeuvre in excess of 15 minutes was significantly correlated with the rates of local tumor recurrence; this phenomenon was explained by the authors through the fact that prolonged ischemia time increases the vulnerability of the residual liver to delayed damage by activating cells signals for local invasion and distant migration (23). Meanwhile, one should not omit the fact that 
Pringle manoeuvre controls the inflow at the level of the liver pedicle, without influencing the backflow from the hepatic veins; therefore, close monitoring of the suprahepatic veins is also mandatory if complex resections are taken into consideration. Moreover, in cases presenting large tumoral volumes developed in the close proximity of the hepatic veins and of the inferior cava vein particular attention should be paid when approaching these structures due to the fact that a rupture at this level might lead to development of a severe air embolism and, secondarily, to cardio-pulmonary collapse (26-29). In such conditions in order to prevent haemorrhagic or embolic accidents, attentive dissection of the hepatic veins and cava vein are needed in order to achieve a good control before initiating the resection phase; moreover, in certain cases intrathoracic approach of the cava vein might be needed in order to preserve the oncological safety of the resection (30). In this respect, in the case we came to present a double abdominal and thoracic approach was the option of choice in order to avoid any dilacerations of the venous structures and meanwhile, not to preclude the oncological safety of the procedure.

\section{Conclusion}

Total vascular exclusion by using a double approach (thoracic and abdominal approach) might be useful in order to increase the safety and effectiveness of typical hepatic resections for giant hepatocellular carcinoma. Therefore, such combined approach seems to decrease the risks of intraoperative accidents and improve the perioperative outcomes. However, one should not omit the fact that prolongation of the time of warm ischemia might have a negative impact on the long-term outcomes; therefore, this time should be shortened as much as possible, without precluding the safety of the procedure.

\section{Conflicts of Interest}

The Authors have no conflicts of interest to declare regarding this study.

\section{Authors' Contributions}

NB, SD and IP performed the surgical procedure; NB, LA and IB reviewed literature data and prepared the draft of the manuscript; IP reviewed the final version of the manuscript. The Authors read and approved the final version of the manuscript.

\section{References}

1 Ferlay J, Shin HR, Bray F, Forman D, Mathers C and Parkin DM: Estimates of worldwide burden of cancer in 2008: GLOBOCAN 2008. Int J Cancer 127(12): 2893-2917, 2010. PMID: 21351269. DOI: 10.1002/ijc. 25516
2 Sherman M: Epidemiology of hepatocellular carcinoma. Oncology 78(Suppl 1): 7-10, 2010. PMID: 20616577. DOI: $10.1159 / 000315223$

3 Bruix J, Sherman M, Llovet JM, Beaugrand M, Lencioni R, Burroughs AK, Christensen E, Pagliaro L, Colombo M and Rodes J: Clinical management of hepatocellular carcinoma. Conclusions of the Barcelona-2000 EASL conference. European Association for the Study of the Liver. J Hepatol 35(3): 421-430, 2001. PMID: 11592607. DOI: 10.1016/s0168-8278(01)00130-1

4 Bruix J and Sherman M: Management of hepatocellular carcinoma: an update. Hepatology 53(3): 1020-1022, 2011. PMID: 21374666. DOI: 10.1002/hep.24199

5 Cho YB, Lee KU, Lee HW, Cho EH, Yang SH, Cho JY, Yi NJ and Suh KS: Outcomes of hepatic resection for a single large hepatocellular carcinoma. World J Surg 31(4): 795-801, 2007. PMID: 17345125. DOI: 10.1007/s00268-006-0359-Z

6 Ba MC, Cui SZ, Lin SQ, Tang YQ, Wu YB and Zhang XL: Resection of a giant hepatocellular carcinoma weighing over ten kilograms. World J Gastroenterol 16(11): 1422-1424, 2010. PMID: 20238412. DOI: 10.3748/wjg.v16.i11.1422

7 Chen XP, Qiu FZ, Wu ZD, Zhang ZW, Huang ZY and Chen YF: Long-term outcome of resection of large hepatocellular carcinoma. Br J Surg 93(5): 600-606, 2006. PMID: 16607679. DOI: $10.1002 / b j s .5335$

8 McKay A, You I, Bigam D, Lafreniere R, Sutherland F, Ghali W and Dixon E: Impact of surgeon training on outcomes after resective hepatic surgery. Ann Surg Oncol 15(5): 1348-1355, 2008. PMID: 18306973. DOI: 10.1245/s 10434-008-9838-9

9 Bacalbasa N, Brezean I, Anghel C, Barbu I, Pautov M, Balescu I and Brasoveanu V: Successful resection and vascular ligation of a large hepatic artery aneurysm - A case report and literature review. In Vivo 31(5): 979-982, 2017. PMID: 28882969. DOI: 10.21873/invivo. 11157

10 Bacalbasa N, Brezean I, Anghel C, Barbu I, Pautov M, Balescu $\mathrm{I}$ and Brasoveanu V: Management of a fulminant upper gastrointestinal bleeding exteriorized through hemobilia due to arteriobiliary fistula between the common bile duct and a right hepatic artery aneurysm - A case report. In Vivo 31(5): 983-989, 2017. PMID: 28882970. DOI: 10.21873/invivo.11158

11 Brasoveanu V, Dumitrascu T, Bacalbasa N and Zamfir R: Splenic artery used for replaced common hepatic artery reconstruction during pancreatoduodenectomy - a case report. Chirurgia (Bucur) 104(4): 499-504, 2009. PMID: 19886062.

12 Brasoveanu V, Anghel C, Barbu I, Pautov M, Ionescu MI, Motthor M, Balescu I, Dima S and Bacalbasa N: Pancreatoduodenectomy en bloc with portal and superior mesenteric artery resection - a case report and literature review. Anticancer Res 35(3): 1613-1618, 2015. PMID: 25750318.

13 Bacalbasa N, Balescu I, Tanase A, Brezean I, Vilcu M and Brasoveanu V: Successful resection of a non-functional paraganglioma with celiac trunk invasion followed by common hepatic artery reimplantation - A case report and literature review. In Vivo 32(4): 911-914, 2018. PMID: 29936479. DOI: 10.21873/invivo.11328

14 Pamecha V, Sasturkar SV, Sinha PK, Mahansaria SS, Bharathy KGS, Kumar S and Rastogi A: Major liver resection for large and locally advanced hepatocellular carcinoma. Indian J Surg 79(4): 326-331, 2017. PMID: 28827907. DOI: 10.1007/s12262-016-1545-3

15 Kusano T, Sasaki A, Kai S, Endo Y, Iwaki K, Shibata K, Ohta M and Kitano S: Predictors and prognostic significance of operative 
complications in patients with hepatocellular carcinoma who underwent hepatic resection. Eur J Surg Oncol 35(11): 1179-1185, 2009. PMID: 19443173. DOI: $10.1016 /$ j.ejso.2009.04.008

16 Vaupel P: The role of hypoxia-induced factors in tumor progression. Oncologist 9(Suppl 5): 10-17, 2004. PMID: 15591418. DOI: 10.1634/theoncologist.9-90005-10

17 Ozaki M and Todo S: Surgical stress and tumor behavior: impact of ischemia-reperfusion and hepatic resection on tumor progression. Liver Transpl 13(12): 1623-1626, 2007. PMID: 18044752. DOI: $10.1002 / 1 \mathrm{t} .21230$

18 Theodoraki K, Papadoliopoulou M, Petropoulou Z, Theodosopoulos T, Vassiliu P, Polydorou A, Xanthakos P, Fragulidis G, Smyrniotis V and Arkadopoulos N: Does vascular occlusion in liver resections predispose to recurrence of malignancy in the liver remnant due to ischemia/reperfusion injury? A comparative retrospective cohort study. Int J Surg 80: 68-73, 2020. PMID: 32619621. DOI: 10.1016/j.ijsu.2020.06.019

19 Belghiti J, Noun R, Zante E, Ballet T and Sauvanet A: Portal triad clamping or hepatic vascular exclusion for major liver resection. A controlled study. Ann Surg 224(2): 155-161, 1996. PMID: 8757378. DOI: 10.1097/00000658-199608000-00007

20 Man K, Fan ST, Ng IO, Lo CM, Liu CL and Wong J: Prospective evaluation of Pringle maneuver in hepatectomy for liver tumors by a randomized study. Ann Surg 226(6): 704-711, 1997. PMID: 9409569. DOI: 10.1097/00000658-19971200000007

$21 \mathrm{Wu} \mathrm{CC}$, Hwang CR, Liu TJ and P'eng FK: Effects and limitations of prolonged intermittent ischaemia for hepatic resection of the cirrhotic liver. Br J Surg 83(1): 121-124, 1996. PMID: 8653335. DOI: 10.1002/bjs.1800830139

22 Hao S, Chen S, Yang X and Wan C: Impact of intermittent portal clamping on the early recurrence of hepatocellular carcinoma after surgery. Surg Today 46(11): 1290-1295, 2016. PMID: 26935546. DOI: 10.1007/s00595-016-1316-6

23 Man K, Ng KT, Lo CM, Ho JW, Sun BS, Sun CK, Lee TK, Poon RT and Fan ST: Ischemia-reperfusion of small liver remnant promotes liver tumor growth and metastases - activation of cell invasion and migration pathways. Liver Transpl 13(12): 16691677, 2007. PMID: 18044786. DOI: 10.1002/lt.21193
24 Cho JY, Han HS, Choi Y, Yoon YS, Kim S, Choi JK, Jang JS, Kwon SU, and Kim H: Association of remnant liver ischemia with early recurrence and poor survival after liver resection in patients with hepatocellular carcinoma. JAMA Surg 152(4): 386392, 2017. PMID: 28052154. DOI: 10.1001/jamasurg.2016.5040

25 Liu S, Li X, Li H, Guo L, Zhang B, Gong Z, Zhang J and Ye Q: Longer duration of the Pringle maneuver is associated with hepatocellular carcinoma recurrence following curative resection. J Surg Oncol 114(1): 112-118, 2016. PMID: 27122256. DOI: $10.1002 /$ jso. 24271

26 van Gulik TM, de Graaf W, Dinant S, Busch OR and Gouma DJ: Vascular occlusion techniques during liver resection. Dig Surg 24(4): 274-281, 2007. PMID: 17657152. DOI: 10.1159/000103658

27 Huguet C, Addario-Chieco P, Gavelli A, Arrigo E, Harb J and Clement RR: Technique of hepatic vascular exclusion for extensive liver resection. Am J Surg 163(6): 602-605, 1992. PMID: 1595841. DOI: 10.1016/0002-9610(92)90567-b

28 Elias D, Dube P, Bonvalot S, Debanne B, Plaud B and Lasser P: Intermittent complete vascular exclusion of the liver during hepatectomy: technique and indications. Hepatogastroenterology 45(20): 389-395, 1998. PMID: 9638412.

29 Bismuth H, Castaing D and Garden OJ: Major hepatic resection under total vascular exclusion. Ann Surg 210(1): 13-19, 1989. PMID: 2742411. DOI: 10.1097/00000658-198907000-00002

30 Si-Yuan F, Yee LW, Yuan Y, Sheng-Xian Y, Zheng-Guang W, Gang H, Meng-Chao W and Wei-Ping Z: Pringle manoeuvre versus selective hepatic vascular exclusion in partial hepatectomy for tumours adjacent to the hepatocaval junction: a randomized comparative study. Int J Surg 12(8): 768-773, 2014. PMID: 24907420. DOI: 10.1016/j.ijsu.2014.05.068

Received November 3, 2020

Revised December 14, 2020

Accepted December 16, 2020 